Rakenteiden Mekaniikka (Journal of Structural Mechanics) vol. 52, nro 4, 2019, s. 236-243

http://rakenteidenmekaniikka.journal.fi/index

https://doi.org/10.23998/rm.76262

(c) 2019 kirjoittajat

Vapaasti saatavilla CC BY 4.0 -lisenssin mukaisesti

\title{
Jännitysväsymisen kontinuumimalli
}

Tero Frondelius, Terhi Kaarakka ${ }^{1}$, Osmo Kaleva, Reijo Kouhia, Heikki Orelma, Joona Vaara

Tiivistelmä. Artikkelissa tarkastellaan evoluutioyhtälöpohjaisen jännitysväsymismallin stokastista laajennusta. Esitetty malli on muodostettu yleisten kontinuumimekaniikan periaatteiden mukaisesti ja on siten luonnostaan moniakselinen ja käsittelee kaikki jännityskomponentit ekvivalentilla tavalla. Malli soveltuu myös mielivaltaiselle kuormitushistorialle. Esimerkkinä tarkastellaan yksinkertaista valkoisella kohinalla häirityn säännöllisen kuormituksen aiheuttaman elinikäennusteen jakaumaa.

Avainsanat: väsyminen, kontinuumimalli, äärellinen elinikä, väsymispinta, vaurionkasvu

Vastaanotettu 31.10.2018. Hyväksytty 10.2.2019. Julkaistu verkossa 31.12.2019.

\section{Johdanto}

Väsymislaskenta on sekä tietokoneiden laskentatehon kasvun että modernien materiaalitestausmenetelmien ansiosta kehittynyt nopeasti viimeisten vuosikymmenien aikana. Luonnollisesti pyrkimys kestävämpiin ja optimaalisempiin rakenteisiin on haastanut tutkijoita myös tarkastelemaan uusia teoreettisia malleja.

Operatiivisessa laskennassa edelleen laajassa käytössä olevien Findleyn ja Dang Vanin väsymiskriteerien (katso [13]) tehokkaan käytön takana on juuri tietokonelaskennan hyödyntäminen. Vaikka kriteerien pohjalta pystytäänkin tyydyttävään väsymisilmiön käsittelyyn, on niillä tiettyjä perustavaa laatua olevia rajoituksia, joihin tutkijat ovat etsineet viime aikoina ratkaisua. Eräs tällainen on syklin määrittelemisen tarve kriteereitä sovellettaessa. Luonnollisesti tämä vaatimus sopii huonosti tilanteeseen, missä jännitysvaihtelut eivät muodosta säännöllistä sykliä, esimerkkinä mainittakoon aaltokuormien aiheuttamat rasitukset.

Viime aikoina kasvavan mielenkiinnon ja tutkimuksen kohteena on ollut Lundin yliopiston tutkijoiden esittämä jännitysväsymisen kontinuumimalli [11], katso myös [1, 2]. Malli perustuu kestävyyspinnan ja sen liikkumista kuvaavien evoluutioyhtälöiden hyödyntämiseen jolloin väsyminen ymmärretään prosessina eikä tiettyjen jännityssyklien muodostamana kriittisenä tilana. Evoluutioyhtälöperustainen lähestymistapa mahdollistaa mallin luontevan laajentamisen ottamaan huomioon $\mathrm{mm}$. materiaalin anisotropian ja

${ }^{1}$ Vastuullinen kirjoittaja: terhi.kaarakka@tuni.fi 
jännitysgradienttien vaikutukset (katso $[6,10]$ ) sekä materiaali- ja jännitysmittauksissa olevat epävarmuudet (katso $[4,15,16]$ ).

Tässä kirjoitelmassa tarkastellaan evoluutioyhtälöpohjaista jännitysväsymismallia tilanteessa, jossa jännitys on stokastinen prosessi. Palataan stokastisten prosessien tematiikkaan tuonnempana, mutta mainittakoon tässä, että kyseiset tilanteet ovat hyvin yleisiä käytännön sovelluksissa. Teorian näkökulmasta klassisen analyysin sijaan käytämme kalkyylissä stokastista analyysiä ja kaikille teorian suureille tulee luonnollinen tilastollinen tulkinta. Stokastinen ajattelu täydentääkin näin artikkelissa [11] esitetyn deterministisen mallin, sillä väsymistarkasteluissa on luonnollista, että kaikki lopputuloksiksi saadut suureet ovat satunnaismuuttujia.

\section{Jännitysväsymisen kontinuumimalli}

Luodaan tässä luvussa lyhyt johdanto artikkelissa [11] esitettyyn malliin. Lähtökohtana on ns. väsymis- tai kestävyyspinnan määritteleminen jännitysavaruuteen. Väsymispinta isotrooppisessa tapauksessa on muotoa

$$
\beta=\frac{1}{\sigma_{-1}}\left(\bar{\sigma}+A I_{1}-\sigma_{-1}\right)=0,
$$

missä $I_{1}$ on jännitystensorin $\boldsymbol{\sigma}$ ensimmäinen invariantti, eli $I_{1}=\operatorname{tr}(\boldsymbol{\sigma})$. Tehollinen jännitys $\bar{\sigma}$ määritellään puolestaan redusoidun deviatorisen jännityksen $s-\boldsymbol{\alpha}$ toisen invariantin avulla muodossa

$$
\bar{\sigma}=\sqrt{3 J_{2}(s-\boldsymbol{\alpha})}=\sqrt{\frac{3}{2} \operatorname{tr}(s-\boldsymbol{\alpha})^{2}} .
$$

Deviatorinen jännitystensori on $\boldsymbol{s}=\boldsymbol{\sigma}-\frac{1}{3} \operatorname{tr}(\boldsymbol{\sigma}) \boldsymbol{I}$, jossa $\boldsymbol{I}$ on yksikkötensori. Deviatorinen tensori $\boldsymbol{\alpha}$ kuvaa väsymispinnan keskiötä jännitysavaruudessa.

Artikkelissa [11, Luku 4] on osoitettu, että kirjoitettaessa yhtälö (1) yksiulotteisen syklisen kuormituksen tapauksessa, jossa jännitys vaihtelee amplitudin $\sigma_{\mathrm{a}}$ verran keskijännityksen $\sigma_{\mathrm{m}}$ ympärillä $\left(\sigma_{\mathrm{m}}-\sigma_{\mathrm{a}} \leq \sigma \leq \sigma_{\mathrm{m}}+\sigma_{\mathrm{a}}\right)$, redusoituu pinta (1) muotoon

$$
\sigma_{\mathrm{a}}+A \sigma_{\mathrm{m}}-\sigma_{-1}=0
$$

joka on Haighin diagrammin lineaarinen osuus. Näin ollen $\sigma_{-1}$ on vaihtokuormituksen väsymisraja $\left(\sigma_{\mathrm{m}}=0\right)$. Reduktio muotoon (2) on seuraus siitä, että väsymispinnan jännityksistä riippuva osuus on astetta yksi oleva homogeeninen funktio.

Edellä esitetty muoto väsymispinnalle (1) on yksinkertaisimpia mahdollisia. On luonnollisesti mahdollista käyttää monimutkaisempia muotoja, mutta tällöin pinnan parametrien määrittämisestä tulee luonnollisesti hankalampaa. Esimerkiksi Brighenti et al. käyttävät artikkelissaan [1,2] väsymispintaa, joka ei ole jännitysten suhteen astetta yksi. Tämä hankaloittaa mallin parametrien määritystä ja lähteessä [1] parametrien estimointiin käytetäänkin geneettistä algoritmia.

Väsymispinnassa (1) esiintyvä tensori $\boldsymbol{\alpha}$ on pinnan keskipiste, jonka kautta pinnan asema määräytyy jännitysavaruudessa. Kontinuumimallin idea on, että väsymispinta liikkuu jännitysavaruudessa ja mukautuu näin vallitsevaan kuormitustilanteeseen. Pinnan liikettä hallitsee evoluutioyhtälö

$$
\dot{\boldsymbol{\alpha}}= \begin{cases}C(\boldsymbol{s}-\boldsymbol{\alpha}) \dot{\beta}, & \text { kun } \beta, \dot{\beta} \geq 0 \\ 0, & \text { muulloin }\end{cases}
$$


Evoluutioyhtälön muodosta nähdään, että tensorin $\boldsymbol{\alpha}$ evoluutio tapahtuu, kun jännitys $\boldsymbol{\sigma}$ liikkuu väsymispinnan ulkopuolella pinnasta poispäin. Evoluutioyhtälössä esiintyvä dimensiottoman materiaaliparametrin $C>0$ estimointiin palataan myöhemmin.

Kontinuumimallin ideana on mitata jännitysväsymistä aiheuttavaa mikrovaurioitumista prosessina. Keskeisenä postulaattina on, että vaurioituminen tapahtuu samanaikaisesti tensorin $\boldsymbol{\alpha}$ evoluution kanssa. Vauriosääntö esitetään tavanomaisesti differentiaaliyhtälönä $\dot{D}=g(D, \beta)$, joka määrää kasvavan funktion $D$ ja joka normeerataan sellaiseksi, että ajanhetki $T_{f}$, jolle $D\left(T_{f}\right)=1$, merkitsee elinikää. Yleisesti käytössä oleva muoto vaurioyhtälölle on

$$
\dot{D}= \begin{cases}\frac{K}{(1-D)^{k}} \exp (L \beta) \dot{\beta} & \text { kun } \beta, \dot{\beta} \geq 0, \\ 0, & \text { muulloin, }\end{cases}
$$

missä $K>0, L>0$ ja $k \geq 0$ ovat materiaaliparametreja. Artikkelissa [11] esitetty muotoilu vaurioehdolle vastaa tapausta $k=0$. Artikkelissa [6] puolestaan tarkastellaan tilannetta $k=1$.

Dimensiottomien materiaaliparametrien $C>0, K>0, L>0$ ja $k \geq 0$ estimointia käsitellään lähteissä $[6,10,11]$. Ideana on määritellä yksiulotteisen vaihtokuorman tapauksessa kestoluku $N=N(C, K, L, k)$, jonka erotukselle mittausarvoista etsitään pienimmän neliösumman ratkaisu. Siinä missä parametrit $\sigma_{-1}$ ja $A$ tuovat malliin informaation äärettömästä eliniästä, tuovat parametrit $C, K, L$ ja $k$ informaation äärellisestä eliniästä.

\section{Jännitysprosessi}

Edellisessä luvussa jännityksen $\boldsymbol{\sigma}$ ajateltiin olevan jokin mitattu deterministinen jännityshistoria. Kuitenkin, jos kyseinen jännitysmittaus pyrittäisiin uusimaan vaikka miten tarkasti, ei lopputulokseksi saataisi täsmälleen samaa jännityshistoriaa. Toistamalla koe uudelleen ja uudelleen, saataisiin edelleen kokoelma hieman toisistaan poikkeavia jännityshistorioita ja luonnollinen kysymys olisi, mille mitatuista jännityshistorioista jännitysanalyysi tulisi sitten perustaa?

Ratkaisun ongelmaa tarjoaa stokastinen analyysi. Ajatellaan kaikkien edellämainittujen jännityshistorioiden olevan yhden stokastisen jännitysprosessin $\boldsymbol{\sigma}(t)$ realisaatioita. Lukija voi syventää tietämystään stokastisista prosesseista esimerkiksi kirjoista [5, 14]. Kerrataan kuitenkin seuraavaksi perusidea.

Olkoon $(\Omega, \Gamma, \mathbb{P})$ todennäköisyysavaruus ja $T$ jokin aikaintervalli, esimerkiksi $T=$ $[0, \infty)$. Stokastinen prosessi on sellainen kuvaus

$$
X: \Omega \times T \rightarrow \mathbb{R}
$$

että jokaisella kiinteällä $t \in T$ funktio

$$
X(\cdot, t)=\mathbf{x}_{t}: \Omega \rightarrow \mathbb{R}
$$

on satunnaismuuttuja. Siten stokastinen prosessi voidaan ymmärtää ajan $t \in T$ indeksoimana satunnaismuuttujaperheenä $\left\{\mathbf{x}_{t}\right\}_{t \in T}$. Jos puolestaan kiinnitetään $\omega \in \Omega$ ja annetaan $t:$ vaihdella, niin funktio $X(\omega, \cdot): T \rightarrow \mathbb{R}$ on stokastisen prosessin otospolku tai realisaatio. Jännitysprosessi on tällöin matriisiarvoinen stokastinen prosessi $\boldsymbol{\sigma}(t)=\left[\sigma_{i j}(t)\right]$, missä $\sigma_{i j}(t)$ ovat yllä olevia reaaliarvoisia stokastisia prosesseja. 
Käytännössä todennäköisyysavaruuden eksplisiittinen esitys on lähes aina tarpeetonta, sillä stokastiikan hallitsemiseksi riittää tuntea prosessin äärellisulotteiset jakaumat ts. jos $t_{1}<t_{2} \cdots<t_{m}$ ovat mielivaltaisia ajanhetkiä, niin riittää tuntea satunnaismuuttujien $\mathbf{x}_{t_{1}}, \mathbf{x}_{t_{2}}, \ldots \mathbf{x}_{t_{m}}$ yhteisjakauma joko kertymäfunktion tai tiheysfunktion avulla lausuttuna tai muuten annettuna.

Kääntäen on voimassa Kolmogorovin syvällinen tulos: jos tunnetaan äärellisulotteisten jakaumien perhe, niin tietyillä säännöllisyysehdoilla ne määräävät yksikäsitteisesti stokastisen prosessin. Tuloksen todistus löytyy esimerkiksi kirjasta [3].

Miten sitten jännitysprosessi $\boldsymbol{\sigma}(t)$ on yhteydessä mitattuun jännityshistoriaan $\tilde{\boldsymbol{\sigma}}(t)$ ? Kuten edellä oli puhetta, niin jokainen jännityshistoria $\tilde{\boldsymbol{\sigma}}(t), t \in T$, on mallina olevan stokastisen prosessin $\boldsymbol{\sigma}(t), t \in T$, realisaatio.

Jos prosessin $\boldsymbol{\sigma}(t)$ määrittelyssä on tuntemattomia parametreja, niin perusidea on estimoida ne siten, että mitattu jännityshistoria $\tilde{\boldsymbol{\sigma}}\left(t_{j}\right), j=1, \cdots, n$, ja vastaavat mallin antamat arvot $\boldsymbol{\sigma}\left(t_{j}\right), j=1, \cdots, n$, sopivat mahdollisimman hyvin yhteen. Yleisimmät estimointimenetelmät ovat pienimmän neliösumman menetelmä sekä suurimman uskottavuuden menetelmä.

\section{Tulosten käsittely}

Olettamalla jännitys $\boldsymbol{\sigma}(t)$ stokastiseksi prosessiksi evoluutioyhtälöstä tulee stokastinen differentiaaliyhtälö eli myös $\boldsymbol{\alpha}(t), \beta(t)$ ja $D(t)$ ovat stokastisia prosesseja. Samoin äärellisen eliniän tapauksessa ehdon

$$
D\left(T_{f}\right)=1
$$

antama elinikä $T_{f}$ on satunnaismuuttuja. Eliniän stokastiikkaa on tutkittu laajasti, katso esimerkiksi kirja [7]. Suosituimpia eliniän jakaumia ovat Weibullin jakauma ja lognormaali jakauma.

Äskettäin Paolino et al. hyödynsivät lognormaalista jakaumaa. Esimerkkiä seuraten lisäämme evoluutiomalliin oletuksen, että elinikä noudattaa lognormaalista jakaumaa parametrein $\left(\mu, \nu^{2}\right)$, jota merkitsemme $T_{f} \sim \log \mathrm{N}\left(\mu, \nu^{2}\right)$. Tällöin $\ln \left(T_{f}\right) \sim \mathrm{N}\left(\mu, \nu^{2}\right)$.

Aluksi generoimme $N$ kappaletta jännitysprosessin realisaatiota $\left\{\widetilde{\boldsymbol{\sigma}}_{j}(t), t \in T, j=\right.$ $1, \cdots, N\}$, laskemme vastaavat eliniät ja niiden logaritmit $\ln \left(T_{f}^{(1)}\right), \ln \left(T_{f}^{(2)}\right), \ldots, \ln \left(T_{f}^{(N)}\right)$. Koska $\ln \left(T_{f}\right) \sim \mathrm{N}\left(\mu, \nu^{2}\right)$, niin eliniän jakauman parametrien estimaattorit saadaan normaaliin tapaan datapisteiden $\ln \left(T_{f}^{(i)}\right), i=1, \cdots, N$, keskiarvona ja hajontana. Tämän jälkeen elinikään liittyviä todennäköisyyksiä voidaan laskea estimoidun lognormaalisen jakauman avulla.

\section{Esimerkki}

Tarkastellaan jännitysprosessia

$$
\sigma(t)=\sigma_{\mathrm{a}} \sin \left(2 \pi t / t_{\mathrm{p}}\right)+\sigma_{\mathrm{m}}+\tau W(t)
$$

toisin sanoen tavallista vaihtokuormitusta on häiritty pelkällä kohinalla (katso kuva 1), missä $W(t) \sim \mathrm{N}(0,1)$ kaikilla $t$ sekä $W(t)$ ja $W(s)$ ovat riippumattomia kaikilla $t \neq s$. Huomautetaan, että tässä tapauksessa elinikä vastaa vaihtosyklien lukumäärää. Parametri $\tau$ on kohinan intensiteetti ja se voidaan estimoida sinimuotoisesta mittausdatasta $\widetilde{\sigma}(t)$ seuraavasti. Lasketaan ensin puhdas kohina $H(t)$

$$
H(t)=\sigma(t)-\sigma_{\mathrm{a}} \sin \left(2 \pi t / t_{\mathrm{p}}\right)-\sigma_{\mathrm{m}} .
$$




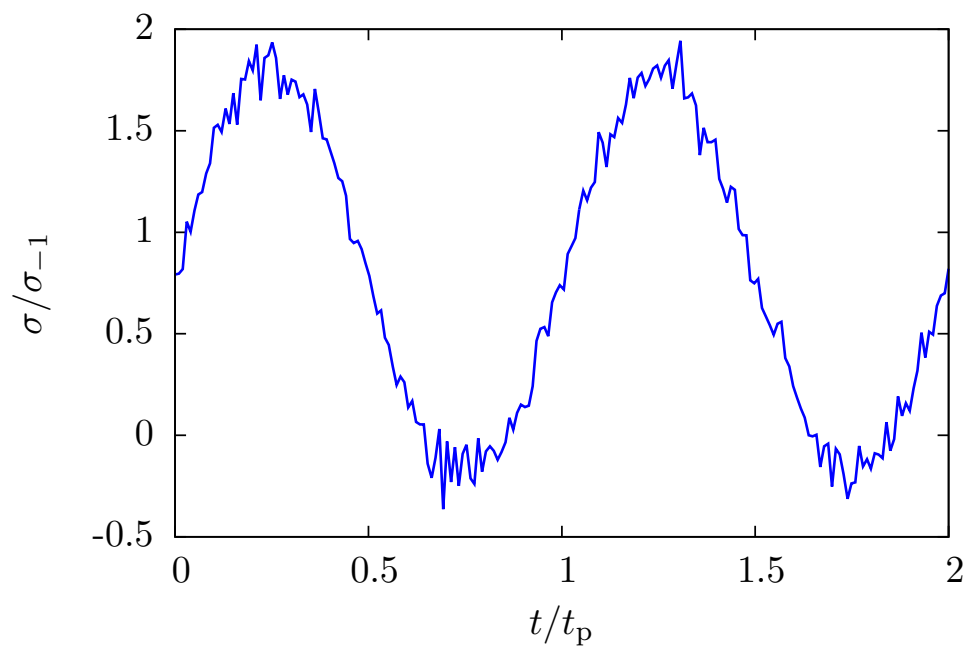

Kuva 1. Näyte tarkasteltavasta jännityshistoriasta.

Tällöin odotusarvo $\mathrm{E}(H(t))=0$,

$$
H(t)=\tau W(t) \sim \tau \mathrm{N}(0,1)=\mathrm{N}\left(0, \tau^{2}\right),
$$

ja intensiteetin estimaattori $\widehat{\tau}$ on kohinaestimaattien $\widetilde{H}\left(t_{i}\right)=\widetilde{\sigma}\left(t_{i}\right)-\sigma_{\mathrm{a}} \sin (2 \pi t)-\sigma_{\mathrm{m}}, i=$ $1, \cdots, n$, hajonta.

Oletetaan materiaaliparametreiksi arvot [11] $\sigma_{-1}=490 \mathrm{MPa}, A=0.025, C=1.25, K=$ $2.65 \cdot 10^{-5}, L=14.4$, jotka kuvaavat AISI-SAE 4340 terästä, sekä kuormituksen keskijännitykselle, amplitudille ja fluktuaatiolle arvot $\sigma_{\mathrm{m}}=0.8 \sigma_{-1}, \quad \sigma_{\mathrm{a}}=\sigma_{-1}$ ja $\tau=0.1 \sigma_{-1}$. Lasketaan 50 realisaatiota jännitysprosessille, jolloin saadaan approksimaatio eliniän logaritmin $\ln \left(T_{f}\right)$ tiheysfunktiolle, kuva 2. Stokastisten differentiaaliyhtälöiden numeerista ratkaisemista on tutkittu laajasti kirjallisuudessa, katso esimerkiksi [8]. Lisäksi on tunnettua, että ongelman stokastinen kompleksisuus riippuu oleellisesti systeemin stokastisesta komponentista ([9]). Käytännössä laskenta vaatii determinististä tapausta enemmän laskenta-aikaa ja tämä huomioon ottaminen algoritmitasolla on mielenkiintoinen tutkimusongelma.

Estimoimalla normaalijakauman parametrit, saadaan $\ln \left(T_{f}\right) \sim \mathrm{N}\left(10.7337,6.239 \cdot 10^{-7}\right)$.

Yllä olevan tiedon pohjalta voidaan vastata suunnittelijoita kiinnostaviin kysymyksiin. Esimerkiksi, mikä on se elinikä, joka tullaan saavuttamaan 95\%:n todennäköisyydellä? Tehtävänä on siis määrittää elinikä $T_{95 \%}$, jolle

$$
\mathbb{P}\left(T_{f}>T_{95 \%}\right)=0.95 .
$$

Tämä voidaan määrittää ekvivalentisti ehdosta

$$
\mathbb{P}\left(T_{f} \leq T_{95 \%}\right)=1-\mathbb{P}\left(T_{f}>T_{95 \%}\right)=0.05 .
$$

Olkoon nyt $\Phi$ normaalijakauman $\mathrm{N}(0,1)$ kertymäfuktio. Tällöin

$0.05=\mathbb{P}\left(T_{f} \leq T_{95 \%}\right)=\mathbb{P}\left(\ln \left(T_{f}\right) \leq \ln \left(T_{95 \%}\right)\right)=\mathbb{P}\left(Z \leq \frac{\ln \left(T_{95 \%}\right)-\mu}{\nu}\right)=\Phi\left(\frac{\ln \left(T_{95 \%}\right)-\mu}{\nu}\right)$ ja siten

$$
\frac{\ln \left(T_{95 \%}\right)-\mu}{\nu}=\Phi^{-1}(0.05)=-1.6449,
$$

josta edelleen seuraa, että

$$
T_{95 \%}=4.5817 \cdot 10^{4}
$$




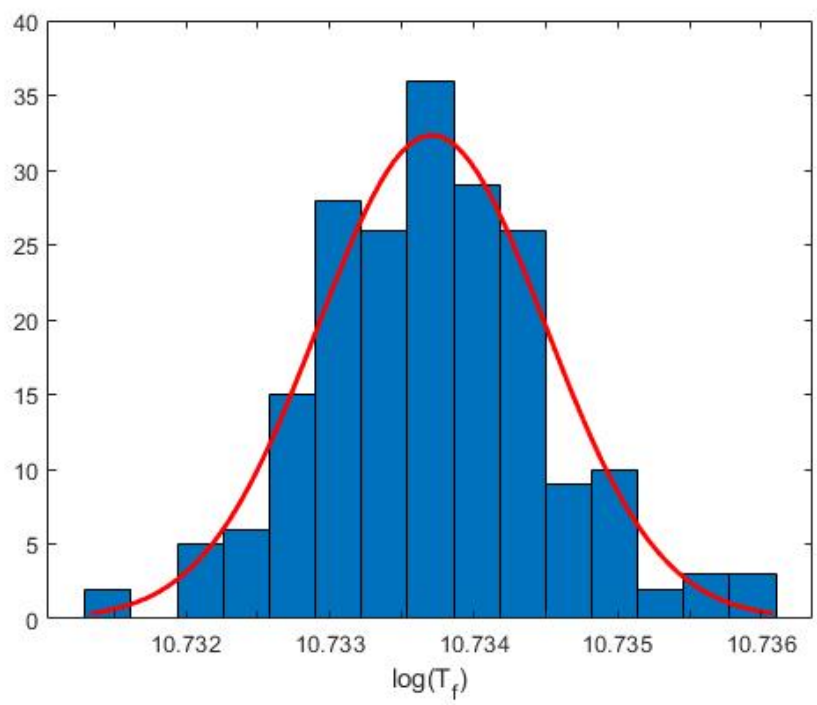

Kuva 2. Histogrammiapproksimaatio eliniän logaritmin tiheysfunktiolle.

\section{Yhteenveto}

Jännitysväsymisen kontinuumimalli on vuonna 2008 julkaistu (katso [11]) differentiaaliyhtälöihin perustuva tapa mallintaa korkeasyklistä väsymisilmiötä. Menetelmän ideana on määritellä jännitysavaruudessa väsymispinta, jonka liikettä hallitsee evoluutioyhtälö. Pinta liikkuu ainoastaan silloin, kun jännitys liikkuu pinnan ulkopuolella pinnasta pois päin. Täsmälleen tällöin oletetaan myös vaurion lisääntyvän. Vaurion kehittyminen mallinnetaan vaurioehdolla, joka on kasvava reaalifunktio saaden arvoja välillä $[0,1]$. Ajanhetki, jolloin vaurioehto saavuttaa arvon yksi, sanotaan olevan rakenteen elinikä. Kontinuumimallin keskeisinä etuina on luonnollinen moniulotteisen jännitystilan käyttö laskuissa sekä vaurion kasaantumisen ajattelu prosessina, jolloin vaatimusta syklin määrittelystä ei ole. Menetelmä luonnollisesti soveltuu myös tilanteisiin, joissa jännityssykli on määritettävissä.

Kontinuumimalli on parhaillaan aktiivisen tutkimuksen alaisena ja tässä artikkelissa tarkasteltiin sen täydennystä mallintamalla jännitys stokastisena prosessina. Lähtökohtaisesti koko väsymisanalyysi tulisi esittää stokastiikan näkökulmasta, milloin pystytään ottamaan suureiden epävarmuudet paremmin huomioon ja laskuista saaduilla tuloksilla on luonnollinen tilastollinen luonne. Käytännön ongelmissa mittausdatan rajallisuus pakottaa suunnittelija perustamaan arvionsa juuri tähän tiettyyn informaatiomäärään. Stokastisessa näkökulmassa mittausdatasta estimoidulla informaatiolla, pystytään simuloimaan rajattomasti uusia (yhdä todennäköisiä) tapahtumakulkuja, joille suunnittelu voidaan perustaa. Näin voidaan säästää mittausajassa ja pyrkiä käyttämään mittausten lisäksi niiden "piilotettua informaatiota" paremmin hyödyksi.

\section{Kiitokset}

Tässä esitetty tutkimus on osa Business Finlandin tukemaa projektia WIMMA Dnro $1566 / 31 / 2015$. 


\section{Viitteet}

[1] 10. R. Brighenti, A. Carpinteri, S. Vantadori, Fatigue life assessment under a complex multiaxial load history: an approach based on damage mechanics, Fatigue 86 Fracture of Engineering Materials 85 Structures 35 (2) (2012) 141-153. https://doi.org/10. $1111 / \mathrm{j} .1460-2695.2011 .01600 . \mathrm{x}$.

[2] R. Brighenti, A. Carpinteri, N. Corbari, Damage mechanics and Paris regime in fatigue life assessment of metals, International Journal of Pressure Vessels and Piping 104 (2013) 57-68. https://doi.org/10.1016/j.ijpvp.2013.01.005.

[3] H. Cramér, M. R. Leadbetter, Stationary and related stochastic processes, Dover, 2004.

[4] T. Frondelius, T. Kaarakka, R. Kouhia, H. Orelma, J. Vaara, Evolution equation based continuum approach for fatigue, Proc. of IX int. conf. "The problems of dynamics of interaction of deformable media", 01-06.10.2018, Goris, Armenia

[5] I. I. Gikhman, A. V. Skorokhod, Introduction to the theory of random processes, Dover, 1996.

[6] S. Holopainen, R. Kouhia, T. Saksala, Continuum approach for modeling transversely isotropic high-cycle fatigue, European Journal of Mechanics A/Solids 60 (2016) 183195. https://doi.org/10.1016/j. euromechsol.2016.06.007.

[7] W. Nelson, Accelerated Testing, Wiley, 2004.

[8] P. E. Kloeden, E. Platen, (1995). Numerical Solution of Stochastic Differential Equations. Springer. ISBN 0-387-54062-8.

[9] A. Krener, C. Lobry, (1981). The complexity of stochastic differential equations. Stochastics - An International Journal of Probability and Stochastic Processes, 4(3), 193203. https://doi.org/10.1080/17442508108833162

[10] N. Ottosen, M. Ristinmaa, R. Kouhia, Enhanced multiaxial fatigue criterion that considers stress gradient effects, (2018) International Journal of Fatigue, 116, p.128139. https://doi.org/10.1016/j.ijfatigue.2018.05.024.

[11] N. Ottosen, R. Stenström, M. Ristinmaa, Continuum approach to high-cycle fatigue modeling, International Journal of Fatigue, 30 (6) (2008) 996-1006. https://doi. $\mathrm{org} / 10.1016 / \mathrm{j}$.ijfatigue.2007.08.009.

[12] D. S. Paolino, A. Tridello, H. S. Geng, G. Chiandussi and M. Rossetto, Dublex S-N fatigue curves: statistical distribution of the transition fatigue life, Frattura ed Integrità Strutturale, 30 (2014) 417-423. https://doi.org/10.3221/IGF-ESIS.30.50.

[13] R. Rabb, Väsyminen ja todennäköisyysteoria, Juvenes print, Oulu, 2017.

[14] S. Ross, Stochastic processes, Wiley, 1996.

[15] J. Vaara, A. Mäntylä, T. Frondelius. Brief review on high-cycle fatigue with focus on nonmetallic inclusions and forming. Rakenteiden Mekaniikka, 50(3):146-152, 2017. https://doi.org/10.23998/rm.65048. 
[16] M. Väntänen, J. Vaara, J. Aho, J. Kemppainen, T. Frondelius. Bayesian sequential experimental design for fatigue tests. Rakenteiden Mekaniikka, 50(3):201-205, 2017. https://doi.org/10.23998/rm.64924.

Tero Frondelius

Oulun yliopisto, Pentti Kaiteran katu 1, 90014 Oulu

tero.frondelius@oulu.fi

Terhi Kaarakka, Osmo Kaleva, Reijo Kouhia, Heikki Orelma

Tampereen yliopisto, Korkeakoulunkatu 10, 33720 Tampere

s-posti: terhi.kaarakka@tuni.fi,osmo.kaleva@tuni.fi, reijo.kouhia@tuni.fi, heikki.orelma@tuni.fi

Joona Vaara, Tero Frondelius

Wärtsilä Finland Oy, Järvikatu 2-4, 65100 Vaasa

joona.vaara@wartsila.com, tero.frondelius@wartsila.com 